\title{
Perancangan Dashboard Badan Penjaminan Mutu Internal (BPMI) Institut Kesehatan Mitra Bunda Sebagai Sistem Informasi Berbasis Website Responsive
}

\author{
Abdul Rohmad Basar *1, Esmeralda ${ }^{2}$ \\ Jln, Teuku Umar Lubuk Baja Kota Batam Kepulauan Riau 29432. Telp. \\ Program Studi Teknik Informatika, Universitas Ibnu Sina, \\ e-mail: *1.
}

\begin{abstract}
Abstrak
Institut Kesehatan Mitra Bunda merupakan salah satu kampus kesehatan dibatam, yang didalam nya terdapat suatu Badan Penjaminan Mutu Internal yang biasa disebut BPMI. Dalam skripsi ini penulis merancang suatu dashboard (BPMI). Tujuan dari sistem ini adalah mendukung pengembangan kampus digital dengan pengenalan BPMI yang lebih komputerisasi. Sistem ini dapat memberikan alternatif media terbaik dalam memberikan informasi terkait BPMI. Objek penelitian ini dilakukan di bagian Badan Penjaminan Mutu Internal (BPMI). Metode pengembangan sistem Rapid Application Development (RAD) memliki tiga tahapan yaitu Requirement Planning, Design Workshop, Implementation dan sebagai metode pemodelan sistem penulis menggunakan Unified Modeling Language (UML) berupa Usecase diagram, Activity diagram dan Class diagram dan alat perancangan database yang diusulkan berupa website. Dalam penelitian ini, untuk database menggunakan MySql. Hasil penelitian menunjukkan bahwa perancangan dashboard Badan Penjaminan Mutu Internal (BPMI) Institut Kesehatan Mitra Bunda sebagai sistem informasi berbasis website responsive mempermudah mengakses informasi BPMI.
\end{abstract}

Kata kunci-Dashboard, Rapid Application Development (RAD), Unified Modeling Language (UML), Database, BPMI

\begin{abstract}
Institut Kesehatan Mitra Bunda is one of the health campuses in the batam, in which there is an Internal Quality Assurance Agency which is usually called BPMI. In this thesis the writer designed a dashboard (BPMI). The purpose of this system is to support the development of a digital campus with the introduction of a more computerized BPMI. This system can provide the best alternative media in providing information related to BPMI. The object of this research is carried out in the Internal Quality Assurance Agency (BPMI). The Rapid Application Development (RAD) system development method consists of three stages, namely Requirement Planning, Design Workshop, Implementation and as a system modeling method the author uses Unified Modeling Language (UML) in the form of usecase diagrams, activity diagrams and class diagrams and the database design tool proposed is a website. In this study, MySQL was used for the database. The results showed that the dashboard design of the (BPMI) Institut Kesehatan Mitra Bunda as a responsive website-based information system makes it easier to access BPMI information.
\end{abstract}

Keywords - Dashboard, Rapid Application Development (RAD), Unified Modeling Language (UML), Database, BPMI 


\section{PENDAHULUAN}

Sistem Penjaminan Mutu Internal Perguruan Tinggi (SPMI) adalah kegiatan sistemik penjaminan mutu pendidikan tinggi oleh setiap perguruan tinggi secara otonom atau mandiri untuk mengendalikan dan meningkatkan penyelenggaraan pendidikan tinggi secara berencana dan berkelanjutan. (Direktorat Penjaminan Mutu, Dirjen Belmawa, 2018).

Saat ini banyak lembaga atau instansi perguruan tinggi yang belum menggunakan website dalam pengelolaan Sistem Penjaminan Mutu Perguruan Tinggi mereka di Indonesia khususnya Kota Batam. Institut Kesehatan Mitra Bunda adalah salah satu instansi perguruan tinggi swasta yang bergerak dalam bidang Kesehatan. Institut Kesehatan Mitra Bunda mengubah nama Sistem Penjaminan Mutu Internal (SPMI) menjadi Badan Penjaminan Mutu Internal (BPMI) yang bertugas melakukan pengawasan dan pengendalian jaminan mutu dari perguruan tinggi.

Kegiatan di institusi sendiri tidak terlepas dari kebutuhan dokumen, BPMI sendiri masih mengalami kesulitan dalam pengelolaan dokumen. Ini disebabkan pengelolaan dokumen yang dilakukan BPMI masih berbasis file ataupun dilihat secara fisiknya sebagai tumpukan dokumen. Banyak nya dokumen yang ada, ditambah dengan banyak nya dokumen yang tidak lengkap sehingga pencarian dokumen menjadi sulit dan tidak terstruktur, dalam hal ini sering terjadi kekeliruan terhadap dokumen yang akan digunakan. Ini disebabkan karena tidak adanya pengelolaan penyimpanan dokumen yang baik dimiliki oleh pangkalan data BPMI sendiri. Tentunya ini sangat memakan waktu saat mulai mencari dokumen BPMI yang diperlukan. Oleh karena itu maka dibutuhkan sistem informasi BPMI yang dapat membangun pengelolaan dokumen secara real time yaitu dengan menghasilkan informasi jumlah data dengan cepat, efektif, efisien, dan produktif demi kemajuan BPMI Institut Kesehatan Mitra Bunda.

Berdasarkan analisa yang sudah dilakukan maka penulis mengusulkan pembuatan sistem informasi dengan judul "Perancangan Dashboard Badan Penjaminan Mutu Internal (BPMI) Institut Kesehatan Mitra Bunda Sebagai Sistem Informasi Berbasis Website Reponsive". Perancangan dashboard sebagai sistem informasi BPMI diharapkan dapat membantu BPMI dalam pengelolaan dokumen yang lebih baik dengan adanya penyimpanan kedalam sistem. yang nantinya sistem dirancang dapat menjadi penyedia sarana prasarana pengeloaan dokumen online di Institut Kesehatan Mitra Bunda.

\section{METODE PENELITIAN}

A. Data primer

Data primer yang diterima dari sumbernya, yang saat ini melakukan secara langsung ke Badan Penjaminan Mutu Internal Institut Kesehatan Mitra Bunda yang akan dijadikan sebagai bahan penelitian skripsi, salah satu data yang didapat adalah.

1. Data wawancara dengan 3 narasumber.

2. Hasil rekapan data BPMI sebagai sumber untuk melakukan perancangan yang dibuat.

3. Profil Badan Penjaminan Mutu Internal Institut Kesehatan Mitra Bunda.

B. Data Sekunder

Data sekunder yang digunakan dalam penelitian skripsi ini berupa literature pendukung yang berupa:

1. Mengumpulkan data dengan mencari informasi-informasi yang berhubungan dengan penelitian yang dipublikasikan melalui internet berbentuk jurnal penelitian ataupun bentuk karya ilmiah dan laporan kerja praktek di perpustakaan Universitas Ibnu Sina Batam.

2. Kebijakan Mutu Badan Penjaminan Mutu Internal Institut Kesehatan Mitra Bunda. 
3. Pedoman Sistem Penjaminan Mutu Internal oleh Direktorat Penjaminan Mutu, Dirjen Belmawa, Kemristekdikti.

\section{HASIL DAN PEMBAHASAN}

\subsection{Analisa Sistem}

Dalam penyusunan perancangan dashboard sebagai sistem informasi Badan Penjaminan Mutu Internal (BPMI) Institut Kesehatan Mitra Bunda, diharapkan sistem yang dibangun dapat membantu proses pengelolaan dokumen BPMI dengan baik. Dalam pengumpulan data maupun informasi yang diperlukan penulis mendapatkan kebenaran materi uraian pembahasan terdiri dari yaitu:

a. Dari hasil wawancara dapat disimpulkan bahwa BPMI Institut Kesehatan Mitra Bunda belum memiliki dashboard sebagai sistem informasi.

b. Data dokumen BPMI tahun 2020 Institut Kesehatan Mitra Bunda menjadikan dasar penelitian ini.

\subsection{Pemodelan RAD}

Perancangan dashboard BPMI Institut Kesehatan Mitra Bunda menggunakan pengembangan sistem model RAD (Rapid Application Development), RAD memiliki tahapantahapan proses penyelesaian seperti Requirements Planning, Design Workshop dan implementasi berikut penggunaan metode RAD dalam perancangan sistem informasi dashboard BPMI Institut Kesehatan Mitra Bunda.

\subsubsection{Requirements Planning}

Perancangan sistem informasi dashboard BPMI Institut Kesehatan Mitra Bunda bertujuan untuk memberikan kemudahan dalam proses pengelolaan dokumen BPMI dengan baik bagi pangkalan data BPMI dan pihak Institut Kesehatan Mitra Bunda.

a. Sistem yang Berjalan

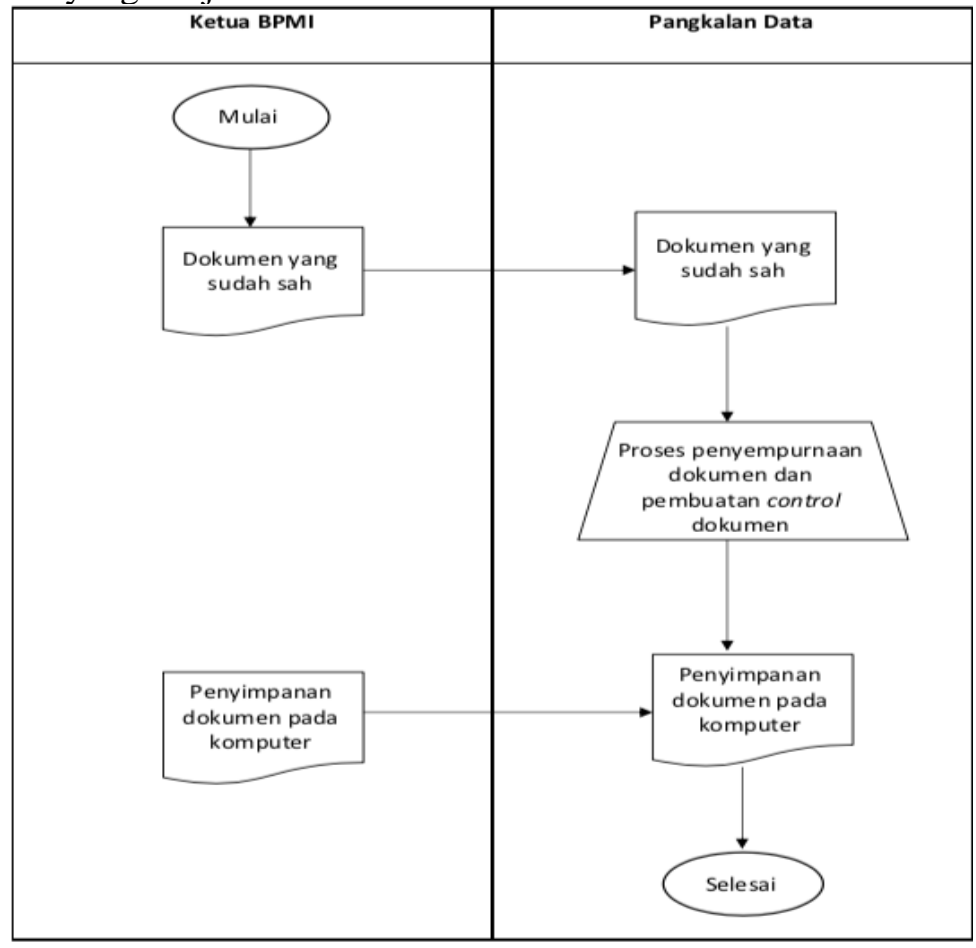

Gambar 1 Sistem yang Berjalan 
b. Sistem yang Diusulkan

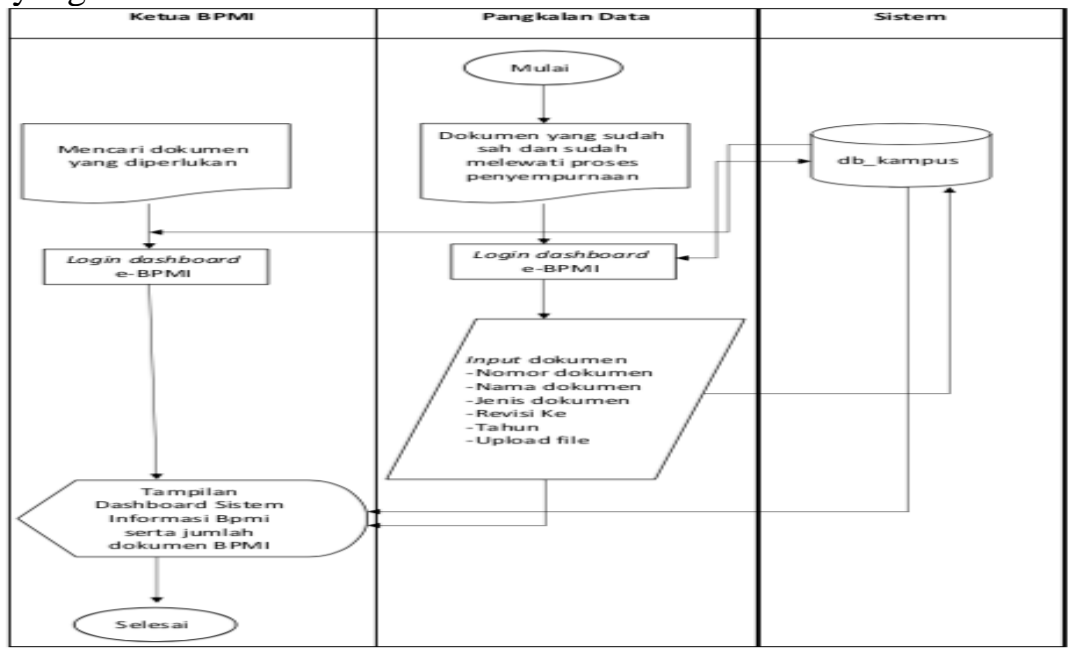

Gambar 2 Sistem yang Diusulkan

\subsubsection{Design Workshop}

Pada tahapan ini peneliti melakukan perancangan sistem informasi dashboard BPMI Institut Kesehatan Mitra Bunda, diharapkan penelitian ini dapat membantu pihak pangkalan data dalam mendapatkan informasi data secara cepat dan Sistem yang Berjalan

\subsubsection{Perancangan Sistem}

Perancangan sistem merupakan tahapan selanjutnya setelah menganalisa sistem yang ada serta mendapatkan gambaran dengan jelas tentang apa yang akan dikerjakan. Untuk mencapai harapan pembuatan sistem, rancangan sistem ini akan digambarkan menggunakan metode UML.

\section{A. Usecase Diagram}

Dibawah ini merupakan gambaran kegiatan apa saja yang dapat dilakukan oleh pengguna sistem terhadap sistem dalam bentuk usecase diagram. Usecase diagram dapat dilihat pada Gambar 3 Use Case Diagram Dashboard BPMI.

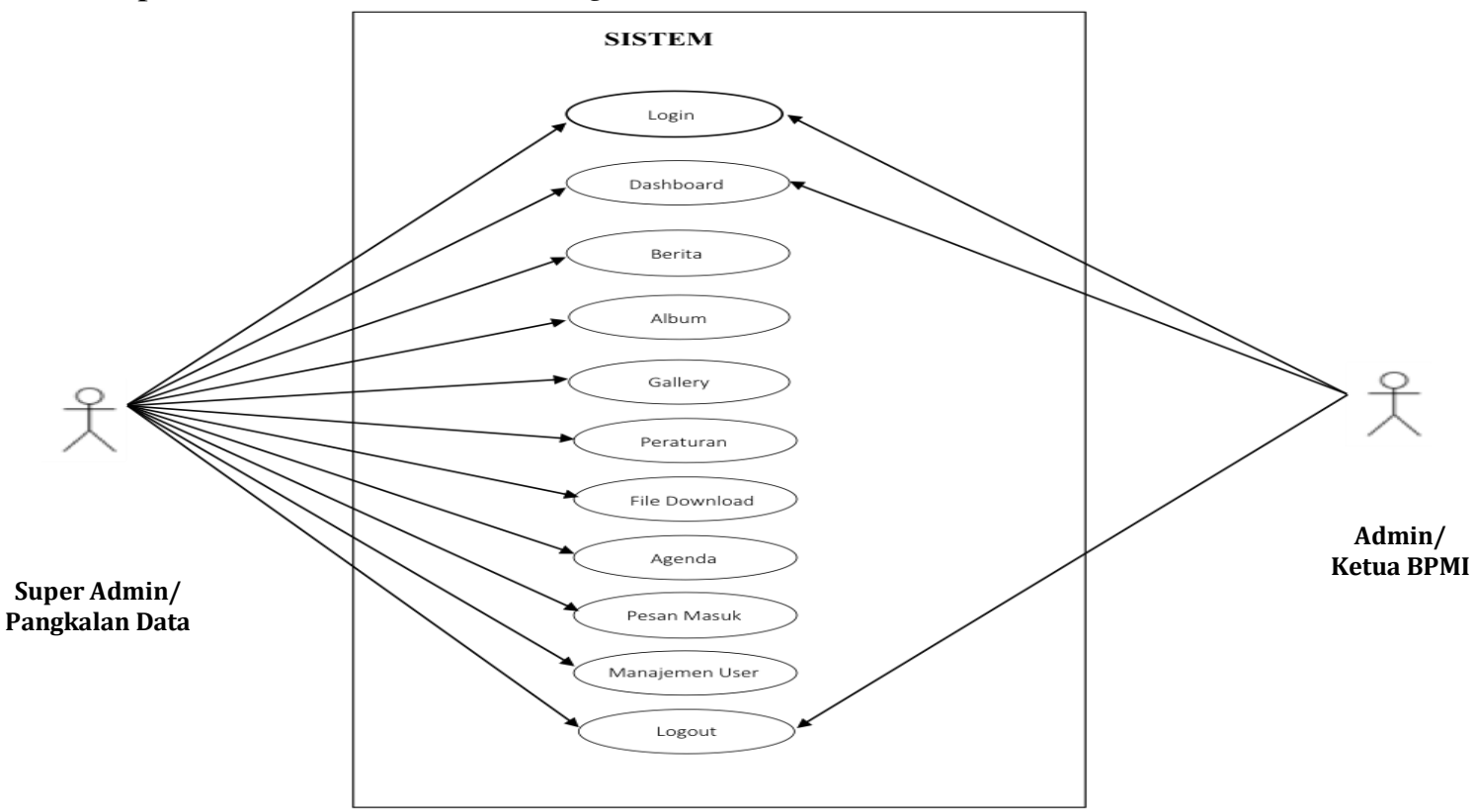

Gambar 3 Use Case Diagram Dashboard BPMI 
B. Activity Diagram

Activity diagram menggambarkan aliran aktivitas di dalam perangkat lunak dibangun, bagaimana masing-masing aliran berawal, keputusan yang akan mungkin terjadi, dan bagaimana mereka berakhir. Pada umumnya activity diagram tidak menampilkan secara detail urusan proses, namun hanya memberikan gambaran global bagaimana urutan prosesnya.

1. Activity Diagram Menu Login Super Admin/Admin

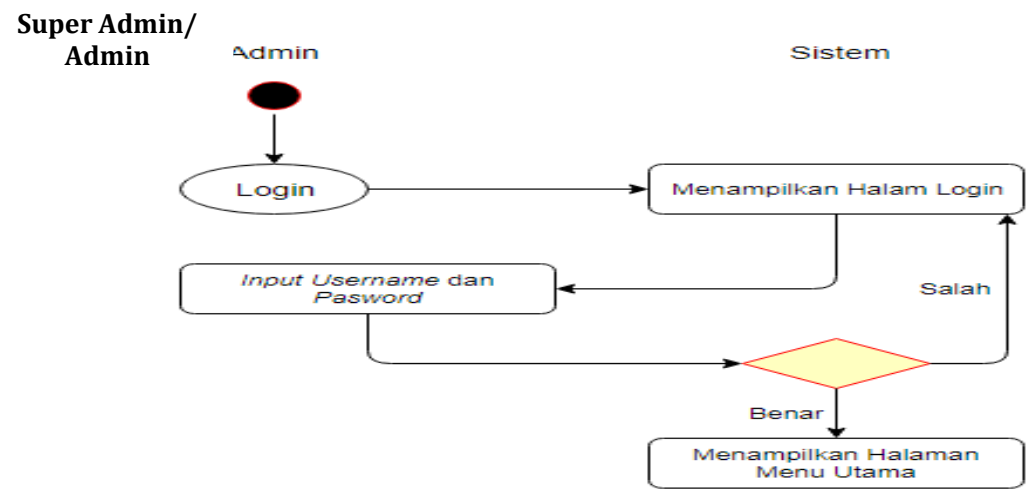

Gambar 4 Activity Diagram Menu Login Super Admin/Admin

2. Activity Diagram Menu Berita

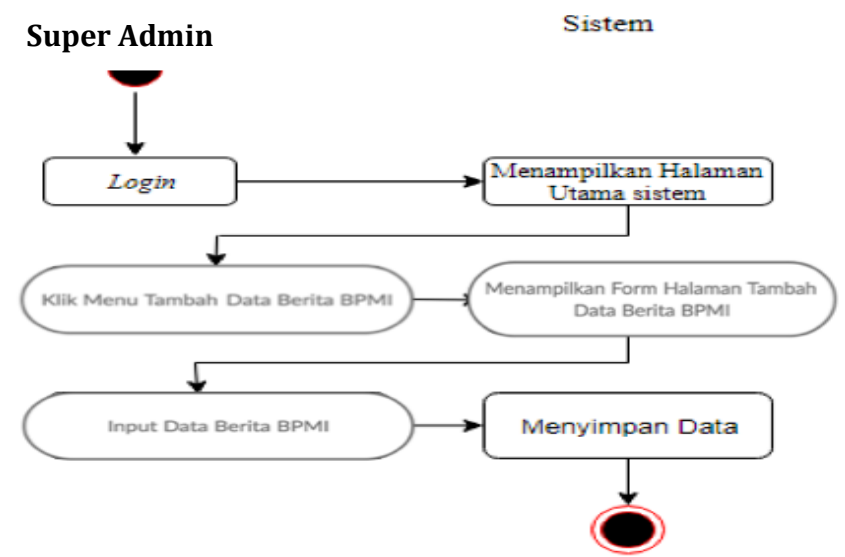

Gambar 5 Activity Diagram Menu Berita

3. Activity Diagram Menu Peraturan

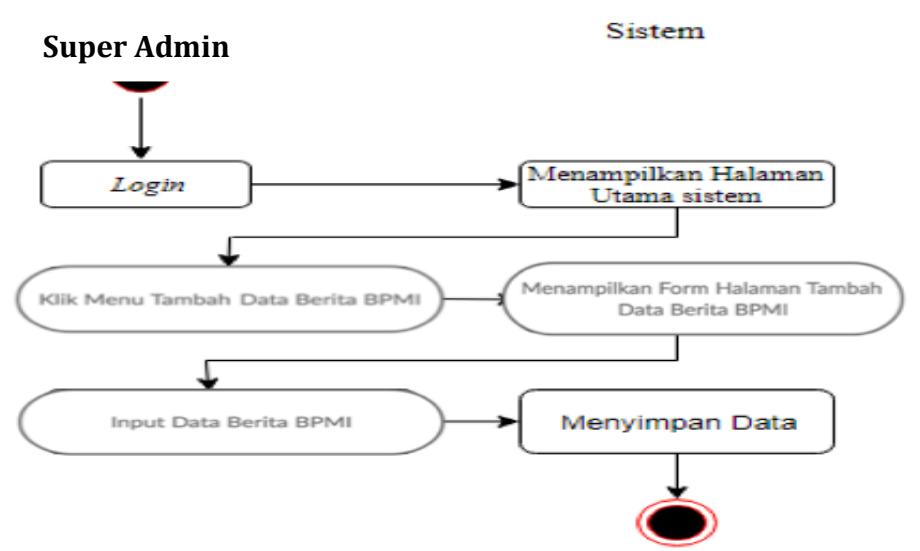

Gambar 6 Activity Diagram Menu Peraturan 
4. Activity Diagram Menu File Download

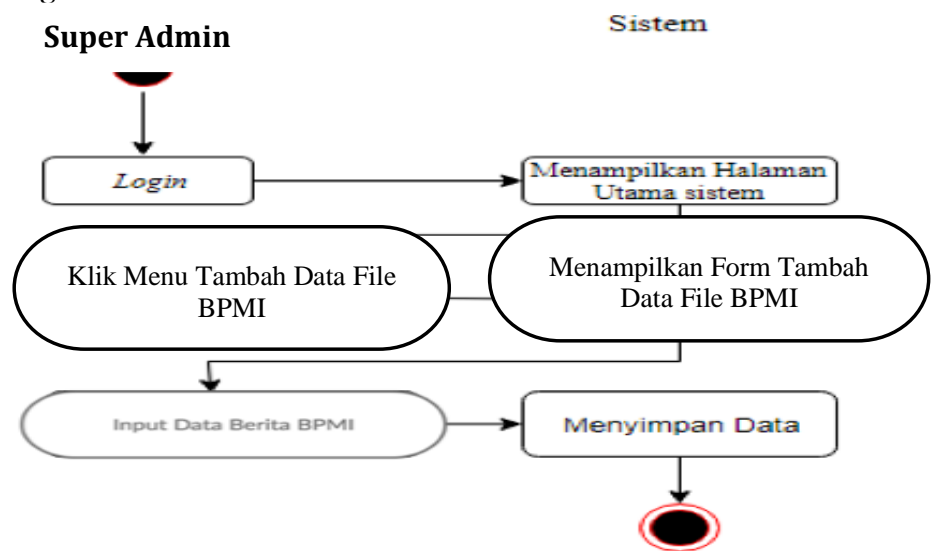

Gambar 7 Activity Diagram Menu File Download

5. Activity Diagram Menu Agenda

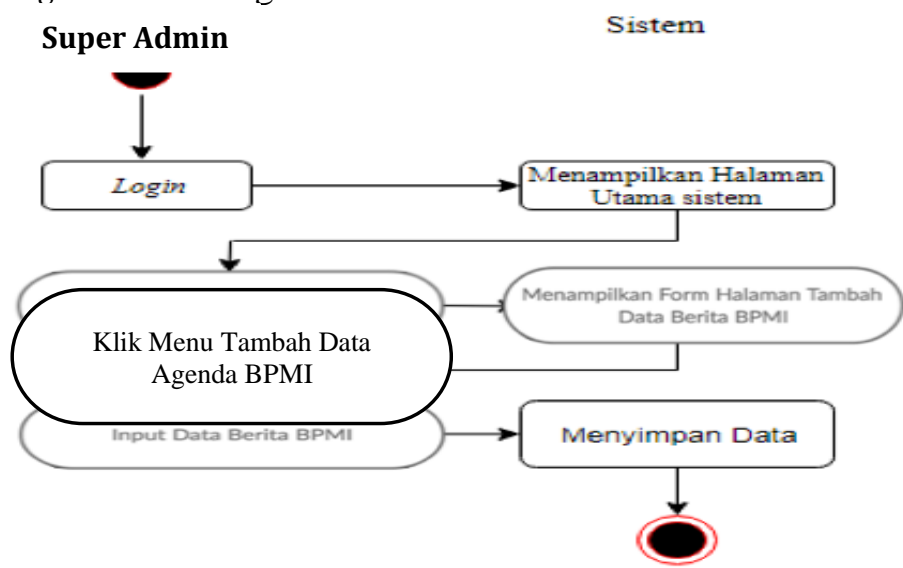

Gambar 8 Activity Diagram Menu Agenda

6. Activity Diagram Menu Manajemen User

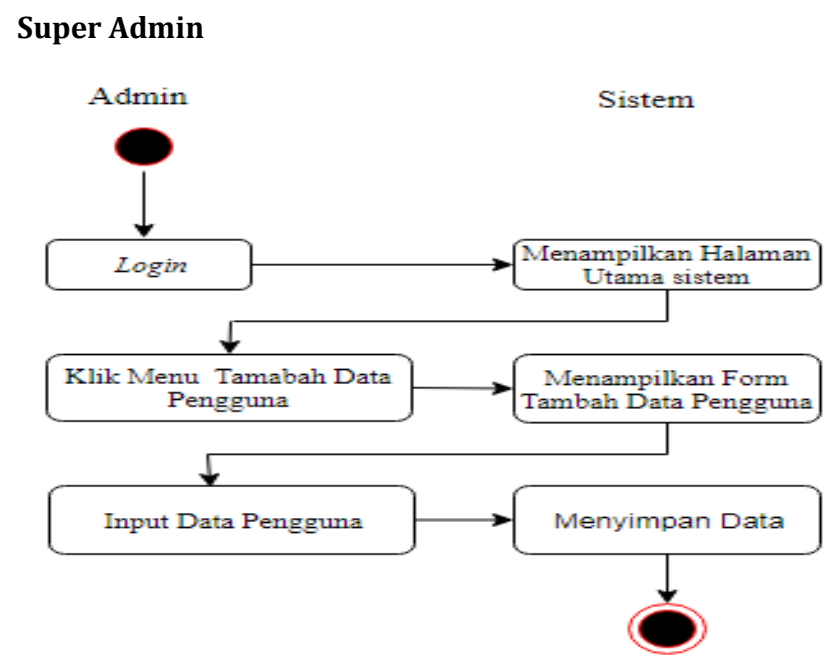

Gambar 9 Activity Diagram Menu Manajemen User 
C. Class Diagram
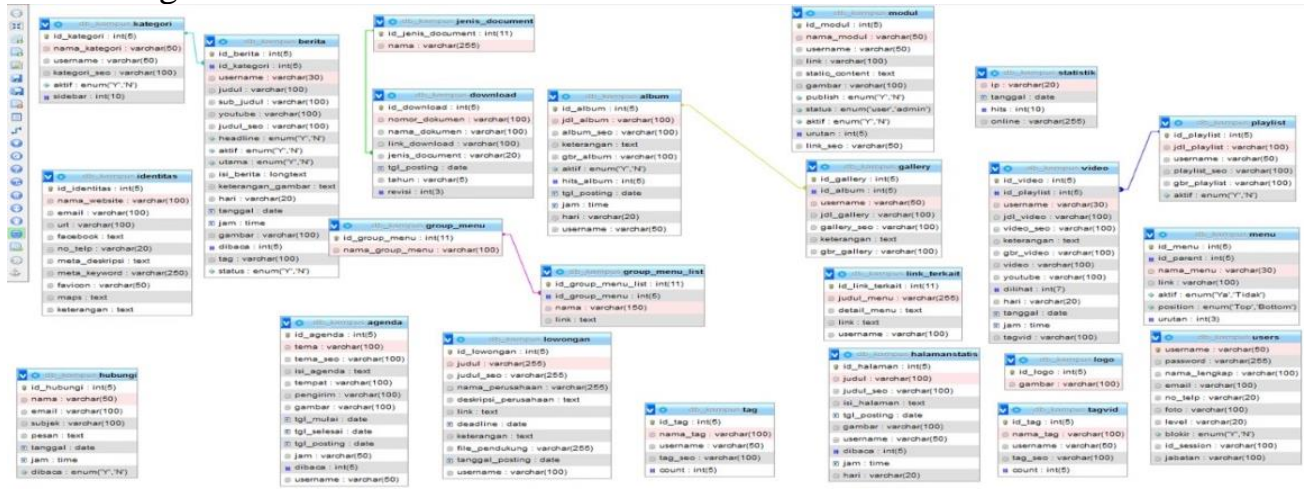

Gambar 10 Class Diagram

\subsubsection{Implementasi}

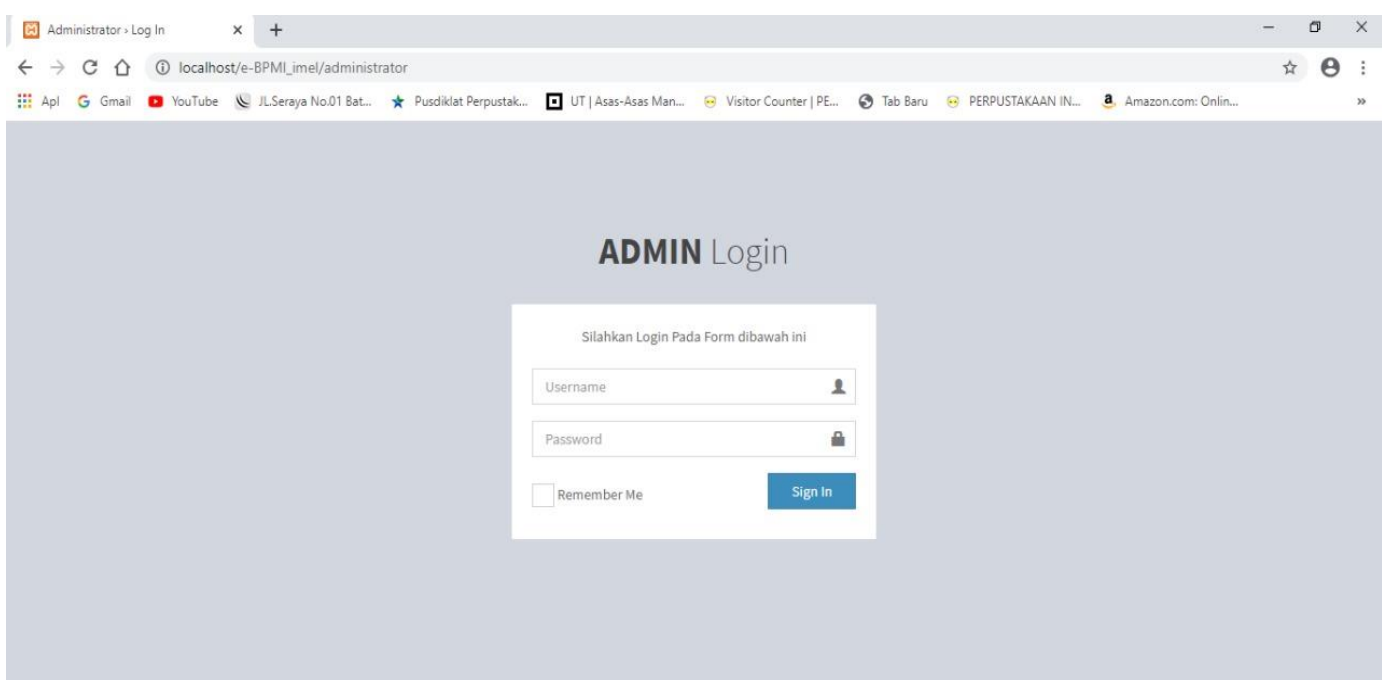

Gambar 14 Tampilan Menu Login

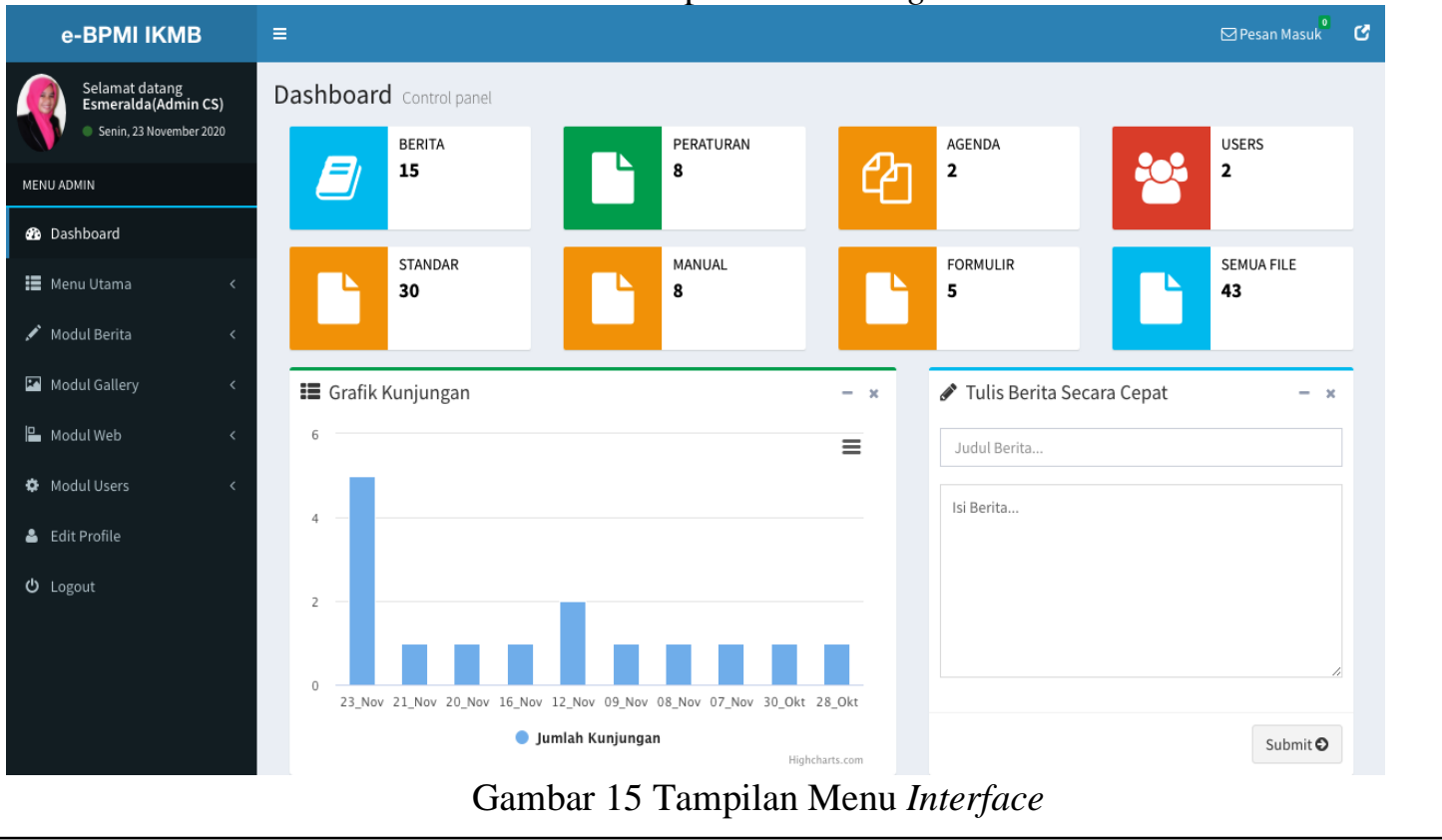




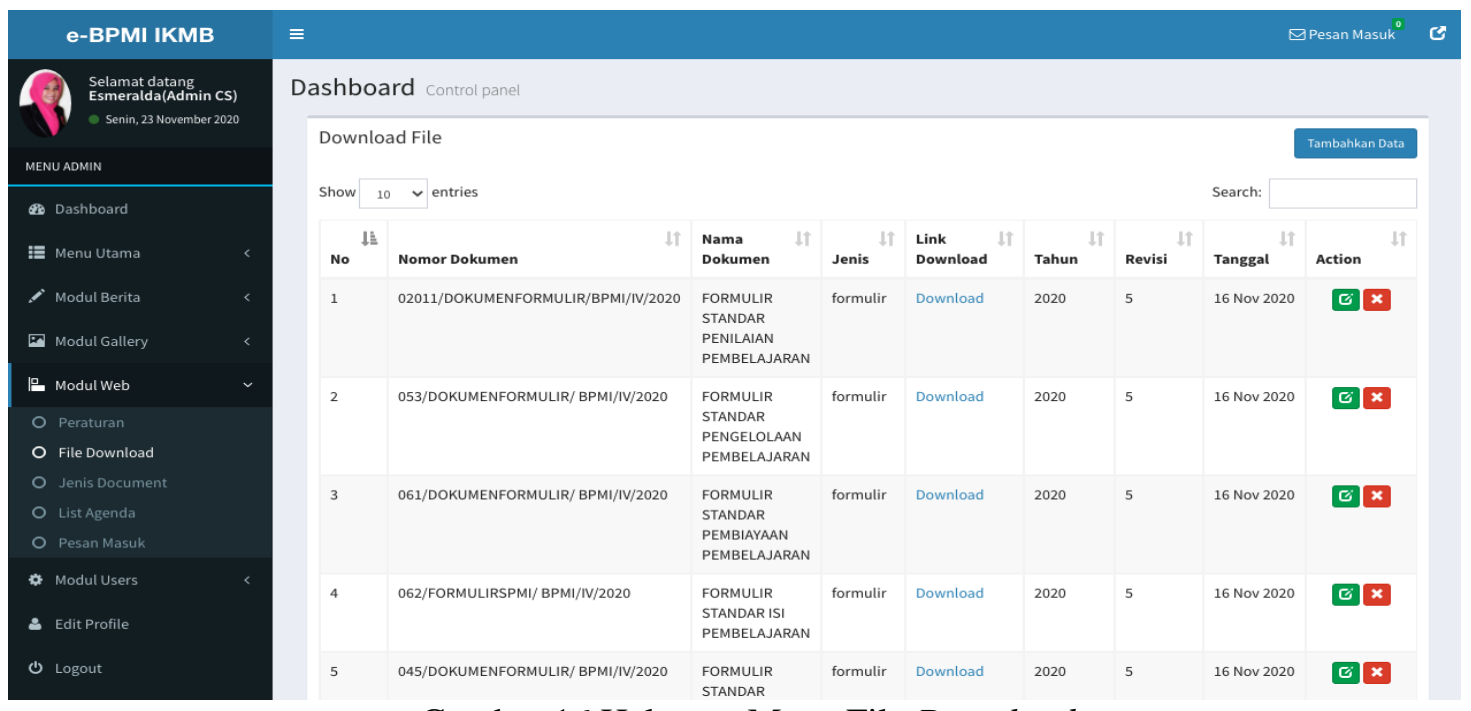

Gambar 16 Halaman Menu File Download

\section{SIMPULAN}

Berdasarkan latar belakang dan rumusan masalah dalam penelitian ini, penulis menyimpulkan beberapa kesimpulan diantaranya adalah:

1. Dashboard Badan Penjaminan Mutu Internal (BPMI) Institut Kesehatan Mitra Bunda dapat membantu penyimpanan dokumen secara online berbasis Website sehingga menjadikan BPMI Institut Kesehatan Mitra Bunda lebih berkembangan dengan menggunakan sistem digital.

2. Hasil rancangan dashboard Badan Penjaminan Mutu Internal (BPMI) Institut Kesehatan Mitra Bunda dapat membantu BPMI dalam mendapatkan dokumen yang diinginkan secara real time yaitu dengan menghasilkan informasi jumlah data dengan cepat, efektif, efisien, dan produktif.

\section{SARAN}

1. Perlunya pelatihan dalam pelaksanaan implementasi program ini sehingga kedepannya data BPMI selalu up to date untuk memberikan informasi kepada pengguna admin.

2. Aplikasi ini perlu dikembangkan dengan rincian algoritma yang lebih baik untuk lebih menarik dan mempuyai daya tersendiri bagi BPMI Institut Kesehatan Mitra Bunda.

\section{DAFTAR PUSTAKA}

[1] Afesia, I., \& Rukun, K. (2018). Perancangan Sistem Pakar Diagnosa Kerusakan Hardware Laptop Di Gama Teknologi Computer. Jurnal Vokasional T Eknik Elektronik a Dan Informatika, 6(2), 2-7.

[2] Alhamidi, A., Iswandy, E., \& Asmara, R. (2019). E-Registrasi Dan Sistem Antrian Pasien Pada Praktek Dokter Di Apotik. Jurnal J-Click, 6(1), 130-144.

[3] Al Fatta, Hanif., (2016:24-26). "Analisa Desain \& Perancangan Sistem Informasi”. Andi, Yogyakarta, 2007

[4] Asmar, A. (2019). Perancangan Aplikasi Edukasi Islami Pengenalan 25 Nama Kisah Nabi 
Dan Rasul Berbasis Android Untuk Kalangan Anak-Anak. Digital Library Teknik Informatika.

[5] BPMI STIKes Mitra Bunda Persada. (2018). Kebijakan Mutu. Batam: STIKes Mitra Bunda Persada.

[6] Direktorat Penjaminan Mutu, Dirjen Belmawa, K. (2018). Pedoman Sistem Penjaminan Mutu Internal - Pend. Akademik, Vokasi, Profesi dan PJJ. Jakarta.

[7] Elisabeth Yunaeti Anggraeni Dan Rita Irviani. (2017:12-15). Pengantar Sistem Informasi. Yogyakarta: Andi Offset. 